\title{
WILLIAM CHESELDEN, SINGULAR LITOTOMISTA Y GRAN ILUSTRADOR INGLÉS DEL SIGLO XVIII.
}

\author{
Juan José Ballesteros Sampol.
}

Servicio de Urología de los Hospitales del I.M.A.S. Barcelona. España.

\begin{abstract}
Resumen.- Se presenta una breve referencia histórica del que fue, probablemente, el más famoso cirujano-urólogo inglés del s. XVIII y que, según, los cronistas posee el "record" en la extracción de un cálculo vesical: entre 24 y 54 segundos, según las fuentes. Es, además, un ejemplo de humanismo tan frecuentemente relacionado con la profesión médica: fue un extraordinario ilustrador de sus propias obras ayudado de la "cámara oscura" tan utilizada por los artistas del Renacimiento, contribuyó al diseño y realización de obra arquitectónica civil, se relacionó con el mundo literario a través de la poesía e influyó decisivamente, merced a sus influencias, en la reforma y separación entre "barberos" y "cirujanos" que ulteriormente concluyó en la creación del Royal College of Surgeons.
\end{abstract}

Palabras clave: Historia de la urología. Litotomía.

Summary.- We present a brief historic reference of who probably was the most famous English urologistsurgeon of the 18th century, and who, following the chronicle writers, holds the record for extraction of a bladder stone (between 24 and 54 seconds). He also was an example of humanism related to the medical profession: he was an extraordinary illustrator of his own books with the help of the "dark chamber", so frequently used by Renaissance artists, contributed to the design and performance of civil architectonic work, had relationships with the literature world through poetry, and decisively influenced the reformation and separation of barbers and surgeons, which ultimately lead to the creation of the Royal College of Surgeons.

Keywords: History of urology. Lithotomy.
Juan José Ballesteros Sampol Borí y Fontestá, $43 \quad 8^{ }-2^{\underline{a}}$ 08017 Barcelona. (España). jballesteros@imas.imim.es

Trabajo recibido: 21 de marzo 2007

\section{Breve sinopsis histórica}

Aunque existen referencias muy antiguas sobre la práctica de la litotomía en India y Persia es, desde Hipócrates (s.V a.C.), que se sabe que tal técnica, prohibida al médico, se dejaba en manos de curanderos practicones y sólo hay alguna referencia a "cirujanos" que la practicaron más adelante como Amonio de Alejandría en el 250 a. de C.

A Aulus Cornelius Celsus (30 a. de C.) se atribuye la primera descripción de la litotomía inclui- 
da en su obra "De re medica libri viri". Se sujetaba al paciente de brazos y piernas en posición de "talla" y un ayudante comprimía enérgicamente el hipogastrio proyectando el cálculo hacia la región perineal. El cirujano introducía sus dedos índice y corazón en el recto para "fijar" el cálculo mientras incindía en el periné sobre la protusión calculosa hasta conseguir un verdadero "parto". Tal técnica se mantuvo sin excesivos cambios hasta el s. XVI en que un italiano, Giovani di Romanis, de Cremona, introdujo la identificación del cuello vesical mediante la introducción de una guía ("aparatus major"). Ese avance anatómico fue difundido por su alumno Marian Sanctus en su libro "Libeles Aureus" y seguido por todos en los tres siglos siguientes.

Los litotomistas, como es sabido, comunmente no eran médicos sino gentes poco formadas, incluso pícaros, que de forma ambulante iban por las poblaciones ofreciendo sus servicios no sin una buena dosis de "atrevimiento". Las intervenciones tenían lugar habitualmente en lugares públicos como las plazas o mercados y especialmente escenificadas por el corajudo litotomista. Se trabajaba, lógicamente, sin anestesia aunque se recurría a peligrosas argucias como sangrar para hipotensar al paciente y producirle un shock para disminuirle el dolor (i!). De cualquier forma se daba principal importancia a la rapidez en efectuar la operación, por razones obvias, de modo que rara vez se tardaban más allá de los 7 minutos.

La principal causa de las complicaciones que se sucedían derivaban de la casi absoluta ignorancia de la anatomía de la región. La penetración en peritoneo o las lesiones intestinales, especialmente en recto, llevaban en no pocas veces a un fatal desenlace del que se podía responsabilizar al actuante imponiéndole penas y multas y siendo expulsado de las ciudades donde actuaban con prohibición de volver a ellas.

Es lógico pensar que el diagnóstico de la litiasis vesical en esos tiempos era bastante impreciso y que, no pocas veces, no se encontrara cálculo vesical alguno... Para tales circunstancias los ya antes mencionados "pícaros" tenían preparada una piedra obtenida en otra de sus actuaciones y que, hábilmente, hacían aparecer en el campo operatorio para justificarse ante los espectadores. Sin embargo, en alguna ocasión, la trampa fue descubierta y le costó la vida al tramposo.

La sucesión de los tiempos y la experiencia dió lugar a mejorar la habilidad y el conocimiento que, no obstante, no se compartía sino que se guardaba celosamente para trasmitir, por tradición, de forma familiar.
En Francia vivió una famosa familia, los Colot, que trasmitió por ocho generaciones sus conocimientos monopolizando la litotomía por 200 años y consiguiendo una alta consideración en el Colegio de Cirujanos.

En Florencia, Thomas Alghisi introdujo, por primera vez, un catéter para drenar la vejiga de los intervenidos lo que publicó en 1707.

En Holanda un controvertido personaje: Johannes Rau que ocupó la cátedra de Anatomía en Leaden afirmaba haber realizado 1.547 litotomías sin ningún óbito (ij!!). Se sabe, sin embargo, que sólo en Amsterdam y sobre 22 pacientes que operó, fallecieron 4 (18,1\%). El ya mencionado Colot le acusó de operar pacientes sin cálculos en la vejiga $y$, en una ocasión, de haber recibido de un ayudante el cálculo "oportuno" para convencer a los espectadores.

Jacques de Beaulieu (1651-1714) desarrolló una variante técnica conocida como " perineotomía lateral" que debía evitar la lesión directa del bulbo uretral y su enojosa hemorragia. Después de múltiples visicitudes llegó al Hotel de Dieu y al Hospital de la Charité donde llegó a realizar sesenta intervenciones en tres meses. Veinticinco pacientes fallecieron y otros veinticinco siguieron hospitalizados por sepsis o anemia por hemorragias. Ante tales resultados se le prohibió seguir operando y abandonó París. Sin embargo siguió su andadura por Holanda y Alemania $y$, parece ser, reivindicó su quehacer con el tiempo a tal punto que regresó a París donde se formó en anatomía y con la ayuda de la ya mencionada sonda guía del cuello vesical efectuó 38 intervenciones sin mortalidad. Su voluntad y decisión le llevaron, de nuevo, por Holanda, Bélgica, Italia y Austria con total reconocimiento. Se le atribuyen, al final de su vida profesional, no menos de 4.500 litotomías y 2.000 hernias. A él se debe una famosa sentencia que, tras la cirugía, dirigía al público que lo presenciaba: "Yo le he extraído la piedra, ahora dejo a Dios que cure al paciente". Seguramente basado en esta sentencia se dice que Roger Couvelaire, ya en pleno s.XX, decía a las familias tras las operaciones: "La ciencia ha hecho todo lo posible, ahora queda en manos de Dios".

De Beaulieu, además,y pese a las contradiciones en su vida acabó siendo un profesional honesto y caritativo. Hizo votos de celibato y pobreza y lo que le quedaba al final de su vida lo repartió entre los pobres y acabó siendo el famoso "Frère Jacques".

Las variantes técnicas en la litotomía vieron la realización de la vía suprapúbica cuando, en 1556, 
Pierre Franco, tras fallar en su intento de intervenir a un muchacho por perineotomía y ante las súplicas de la familia, accedió por vía hipogástrica a través de la vejiga. Sin embargo fue una vía poco utilizada por el temor a entrar en cavidad abdominal y lesionar el intestino.

En nuestro país y en íntima relación con la técnica de la litotomía ocurre un hecho excepcional como es la concesión a Martín de Castellanos de la primera cátedra en la Historia de la Medicina por cédula firmada por el mismo Felipe III: "...la cátedra se erixe, funda e instituye para la enseñanza y práctica de sacar piedras...". Corría el año 1612 a partir del cual cobró quinientos ducados de renta vitalicia y obtuvo títulos y honores para sí y su descendencia.

\section{El personaje}

A caballo entre los s. XVII y XVIII encontramos al protagonista de nuestra historia William Che-

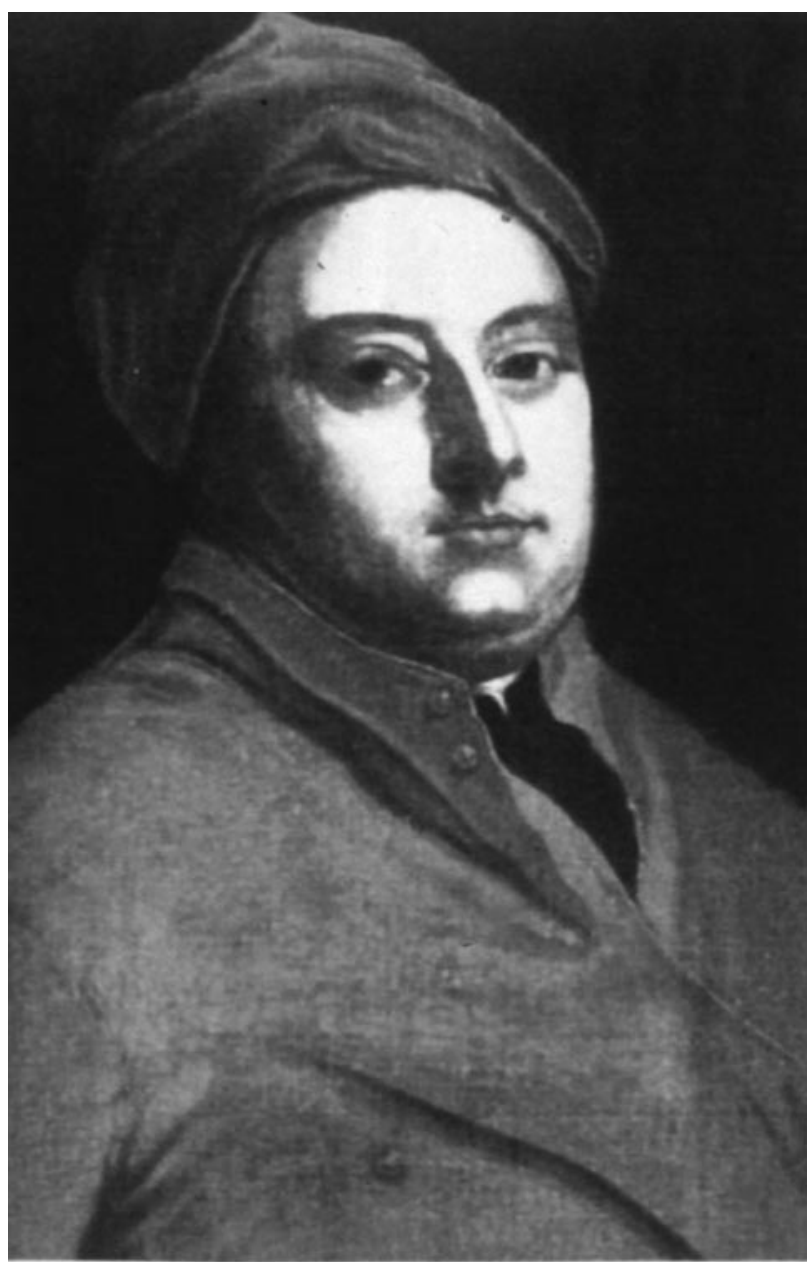

FIGURA 1. Retrato de Cheselden por Richardson. selden (Figura 1) (Leicestershire) (1688-1752). A los 15 años llega a Londres como discípulo de William Cooper, reconocido anatomista, que le trasmitió el interés por la anatomía que completó posteriormente como aprendiz del cirujano James Ferne en el St. Thomas Hospital. Sus crecientes experiencias le llevaron, a la edad de 23 años, a dictar programas de anatomía de 35 lecciones y hasta cuatro cursos por año lo que le sirvió de base, junto a su excelente habilidad para el dibujo anatómico, para editar, dos años más tarde, el manual "The Anatomy of the Human Body" del que se editaron trece ediciones en en Reino Unido, dos en Estados Unidos y una en Alemania. En la actualidad se conservan tres ejemplares de la edición inglesa en la Cowlishaw Collection (Figuras 2, 3 y 4).

Básica para su formación anatómica fueron sus disecciones sobre cadáveres (condenados y criminales ajusticiados) que realizaba en su propio domicilio por carecer de la licencia que para tales actividades otorgaba, entonces, la "Company of Barber Surgeons" (Figura 5).

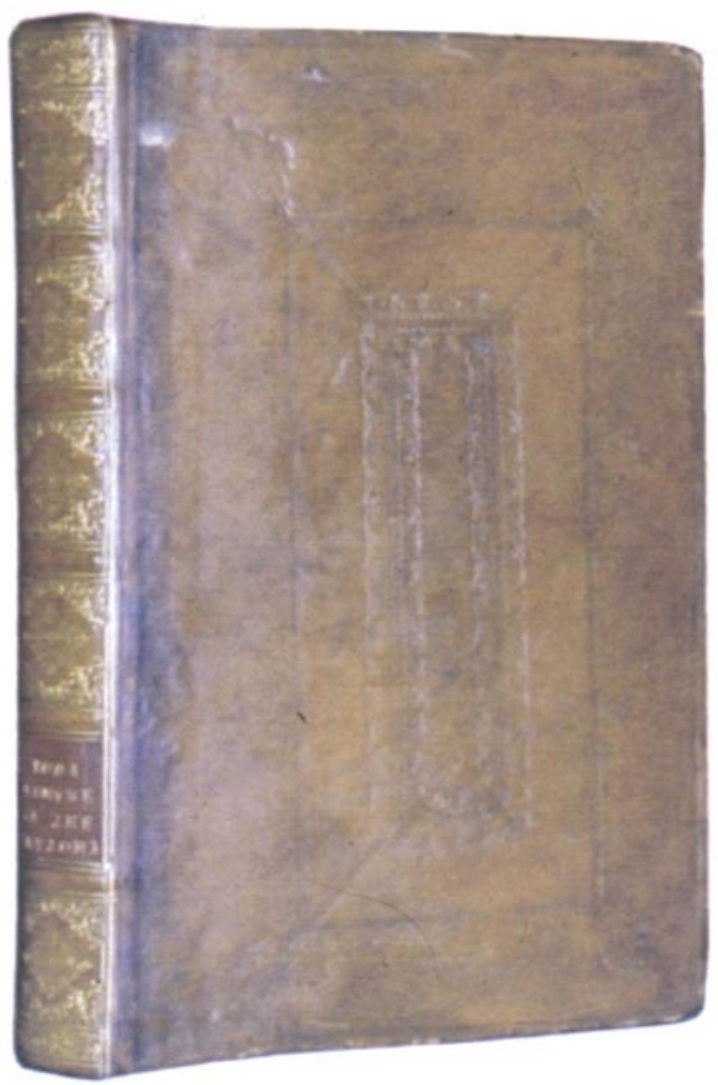

FIGURA 2. Uno de los 3 únicos ejemplares de la

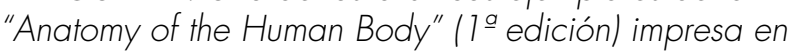
1713 con 23 grabados anatómicos llegados hasta nosotros. 


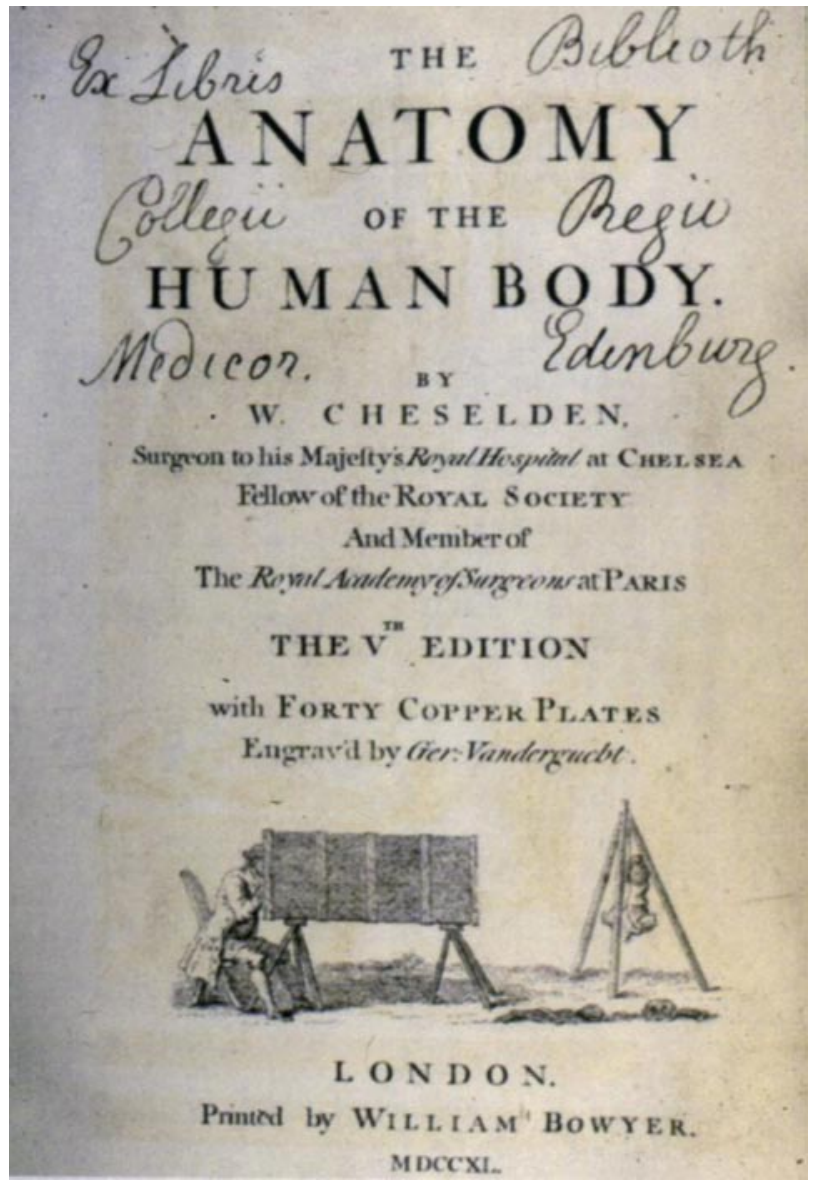

FIGURA 3. Cabecera de una $5^{a}$ edición en la que se observa la ilustración de la cámara oscura tan utilizada por el autor.

A los 30 años se incorporó al staff del St. Thomas e inició la cirugía de la litiasis produciéndose un altercado con John Douglas del Westminster Hospital quien le acusaba de plagio por seguir la técnica de litotomía suprapúbica que él había rescatado e iniciado en 1919 y publicado en 1723 (Lithotomia Douglasiana), el mismo año en que Cheselden hacía lo propio (Treatise on the High Operation for the Stone). El desenlace fue que Cheselden abandonó la vía por considerarla insatisfactoria y recobró la mas tradicional de "Frère Jacques" en la que consiguió una extraordinaria habilidad y brillantez de la que derivó un reducido índice de mortalidad para la época del $9,3 \%$ (20 fallecidos de 213 intervenidos) (Figuras 6 y 7).

Su fama trascendió al continente europeo e importantes instituciones continentales becaban a sus más ilustres miembros para acudir a Londres y aprender la técnica. Se dió la paradoja que la Academia Francesa de la Ciencia (del país que popularizó la

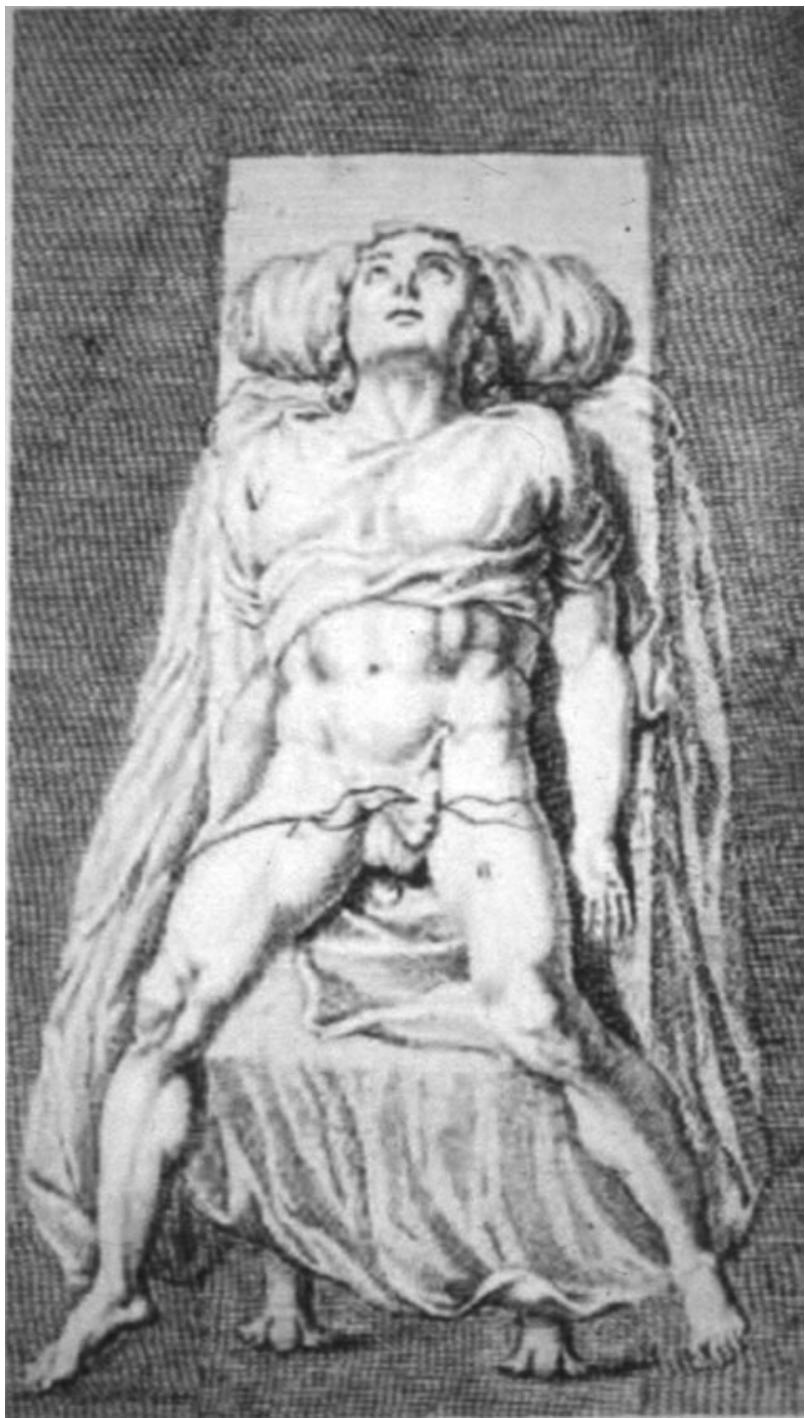

FIGURA 4. Lámina interior de la misma obra.

litotomía perineal) envió a Morand con esa intención y a él debemos el testimonio, que ha hecho popular a Cheselden, de haber presenciado la extracción de un cálculo vesical EN VEINTICUATRO SEGUNDOS (hay alguna otra versión que lo alarga a cincuenta y cuatro) $(i !)$.

Su actividad asistencial se fue multiplicando actuando, además de en el St. Thomas, en el Westminster Infirmary y en el St. George Hospital y se extendió a otras "especialidades" como la cirugía oftálmica en la que extirpó cataratas y describió una "pupila artificial". En cirugía intestinal describió la reparación de la hernia umbilical estrangulada por resección intestinal y colostomía. En su ejercicio privado llegó a cobrar 500 shillings por extirpar un cál- 


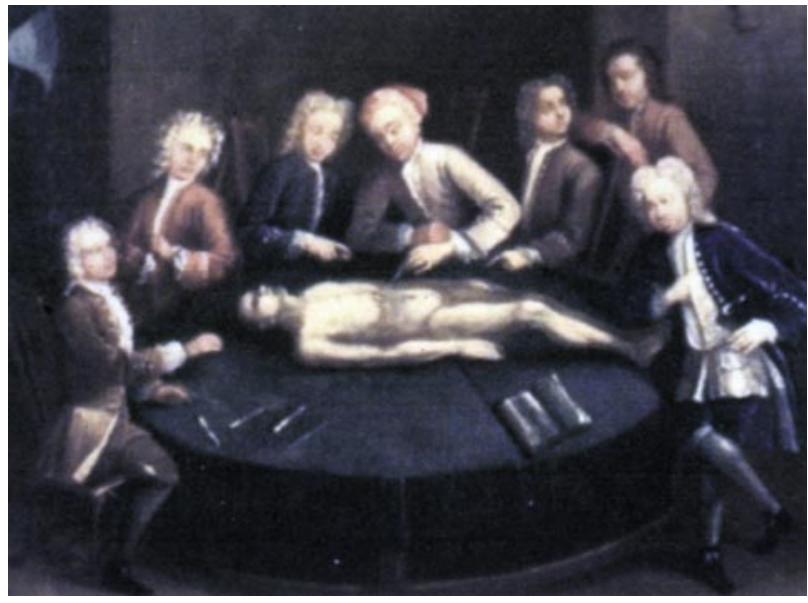

FIGURA 5. Oleo de la época mostrando a W. Cheselden llevando a cabo la disección de un cadáver.

culo (equivalencia aproximada a 1000 euros) y fue cirujano personal de la reina Caroline, esposa de Jorge II y amigo personal del Papa Alejandro y de Isaac Newton. Llegó a ser miembro honorario de la Academie Française des Ciences.

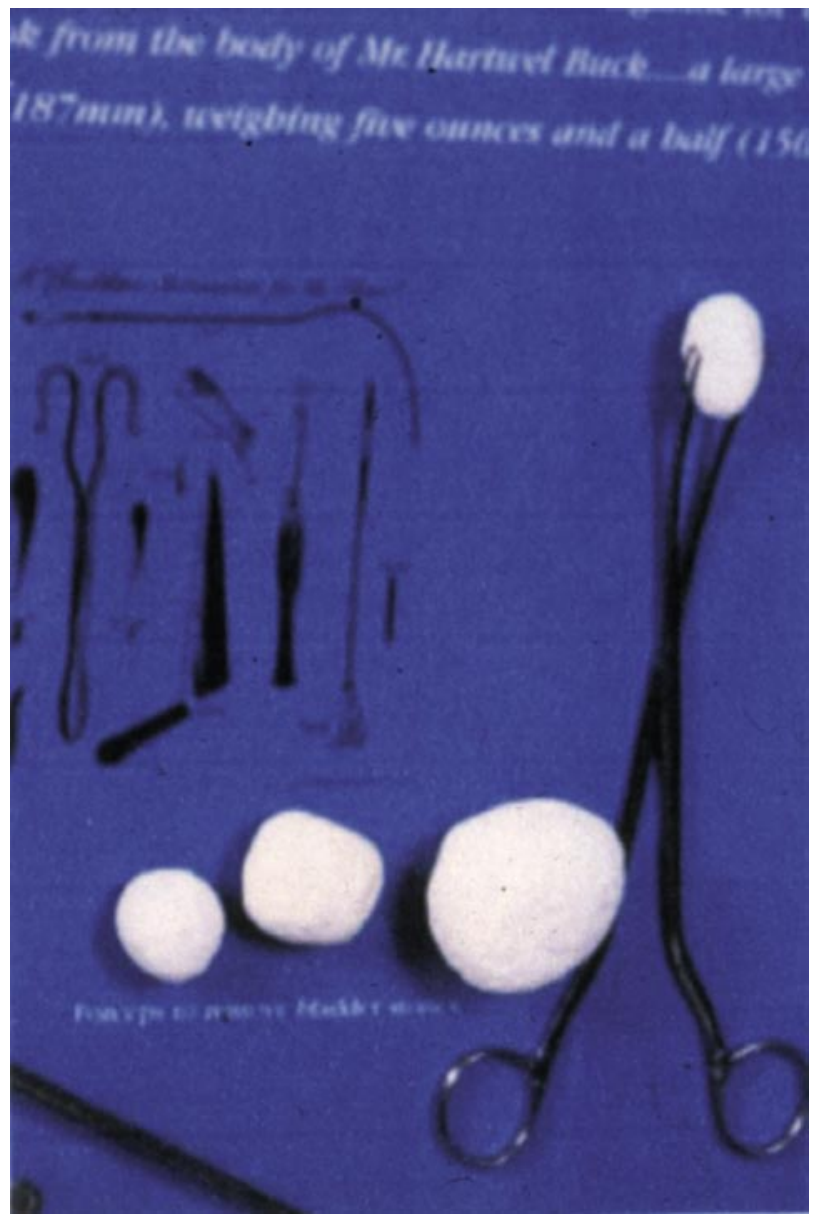

FIGURA 7. Instrumental de Cheselden utilizado en la extracción de cálculos.

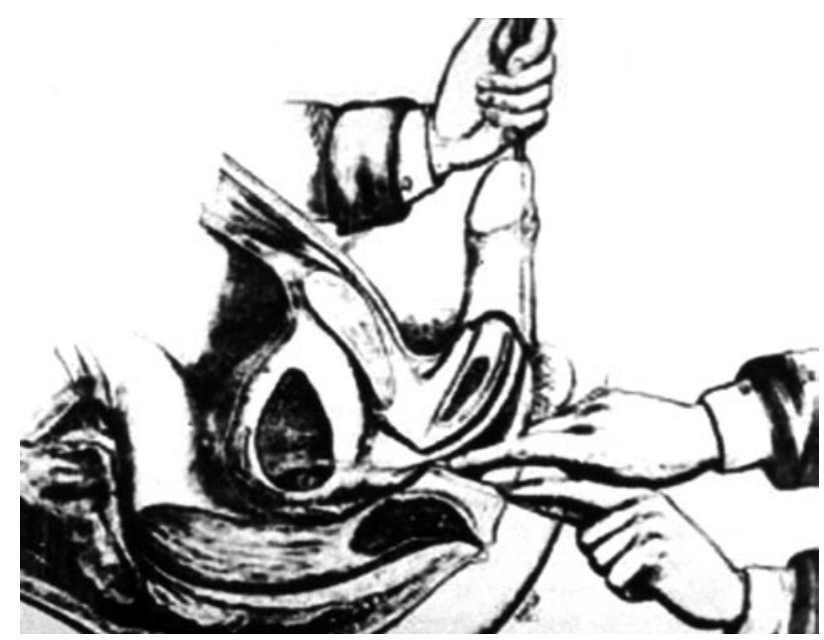

FIGURA 6. Esquema de la litotomía lateral.

En 1773 edita una de sus más importantes obras tanto por su contenido como por sus propias ilustraciones: "Osteographia" que la hicieron la mejor obra ilustrada de su tiempo sobre anatomía del esqueleto humano (Figuras 8 y 9).

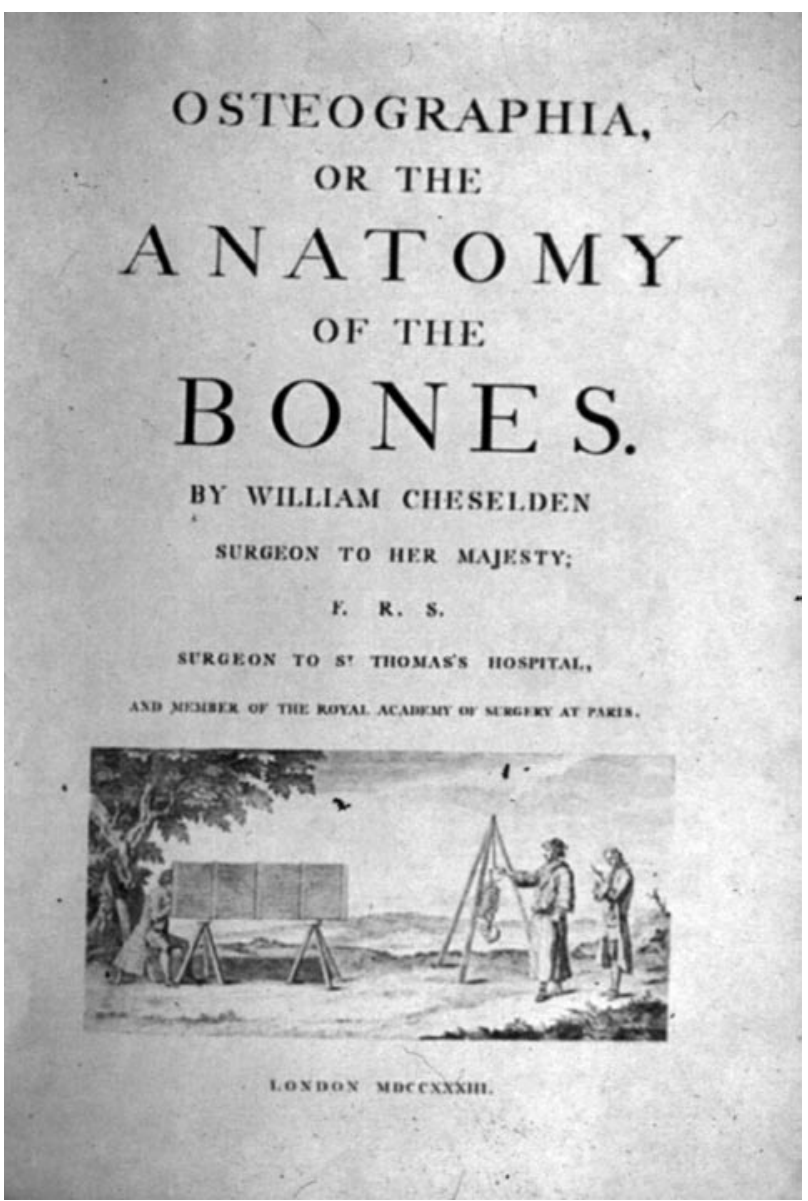

FIGURA 8. Cabecera de su Osteografía (1733). 


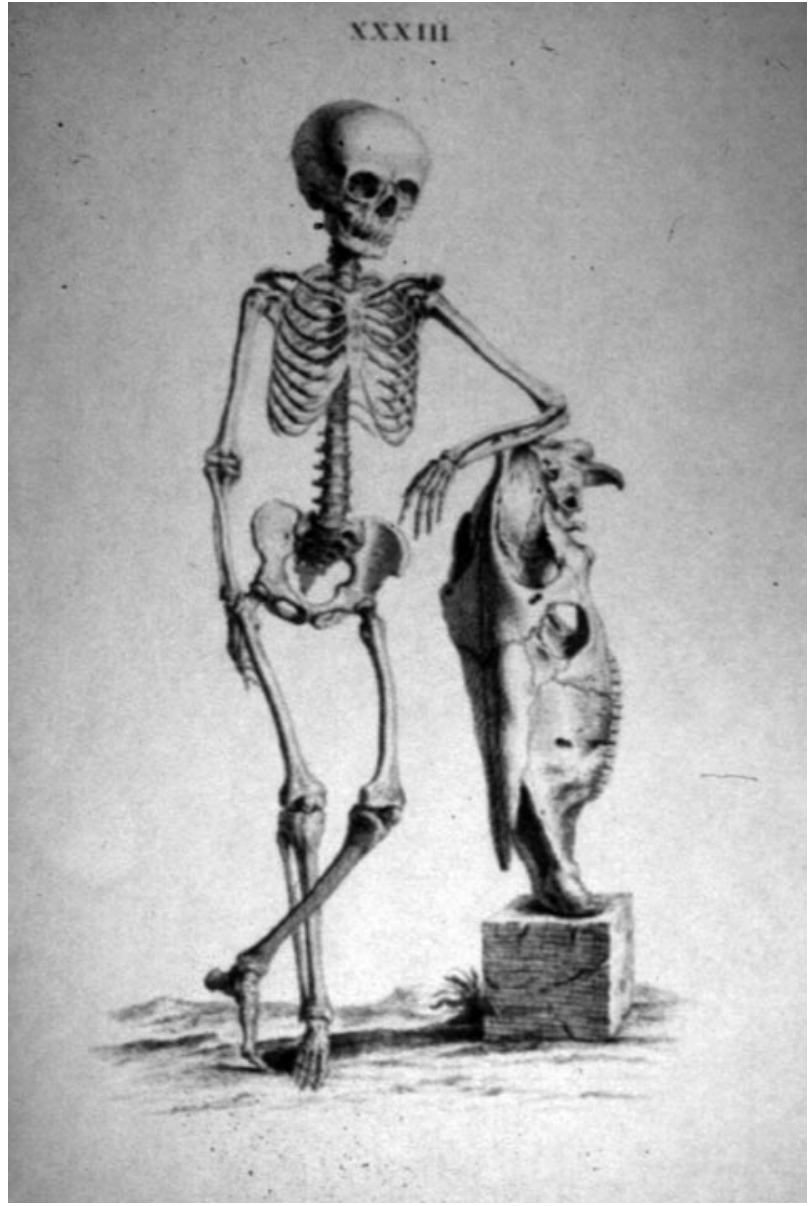

FIGURA 9. Lámina interior con un esqueleto apoyado en el cráneo de un cuadrúpedo.

Su habilidad como dibujante le hizo participar en proyectos de arquitectura civil contribuyendo a la realización de los planos del Fulhembridge y del Surgeons Hall y penetró en ambientes literarios por su afición a la poesía.

Con 50 años limitó su actividad a la de cirujano del Royal Hospital de Chelsea y comenzó su interés por la Barber-Surgeons Company de la que llegó a ser "guardian", propugnando la separación entre "barberos" $y$ "cirujanos", en 1745, para el mejor avance de la Cirugía y que, más tarde, dió lugar a la creación del famoso Royal College of Surgeons of England.

Su inquietud por aplicar los más avanzados conceptos en ilustración, de su tiempo, le llevó a la utilización de la "cámara oscura" con estos fines como ya hicieran Leonardo y Durero en el Renacimiento.

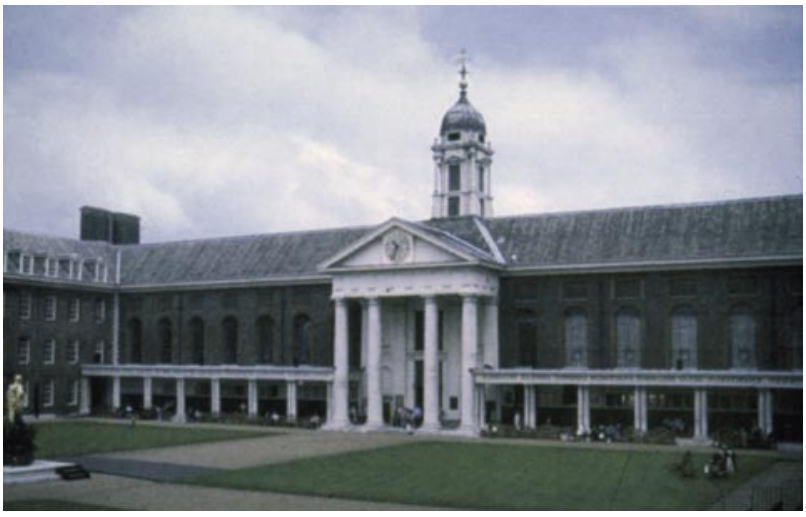

FIGURA 10. Hospital de Chelsea en el 2004. Actualmente se dedica a soldados británicos incapacitados.

Entre sus discípulos hay que citar a Thomas Cadwalader (1708-1789) que realizó el primer curso de disección en la América Colonial y al gran John Hunter (1728-1793) padre de la cirugía moderna y al que se debe, por primera vez, establecer relación de dependencia entre la presencia de los

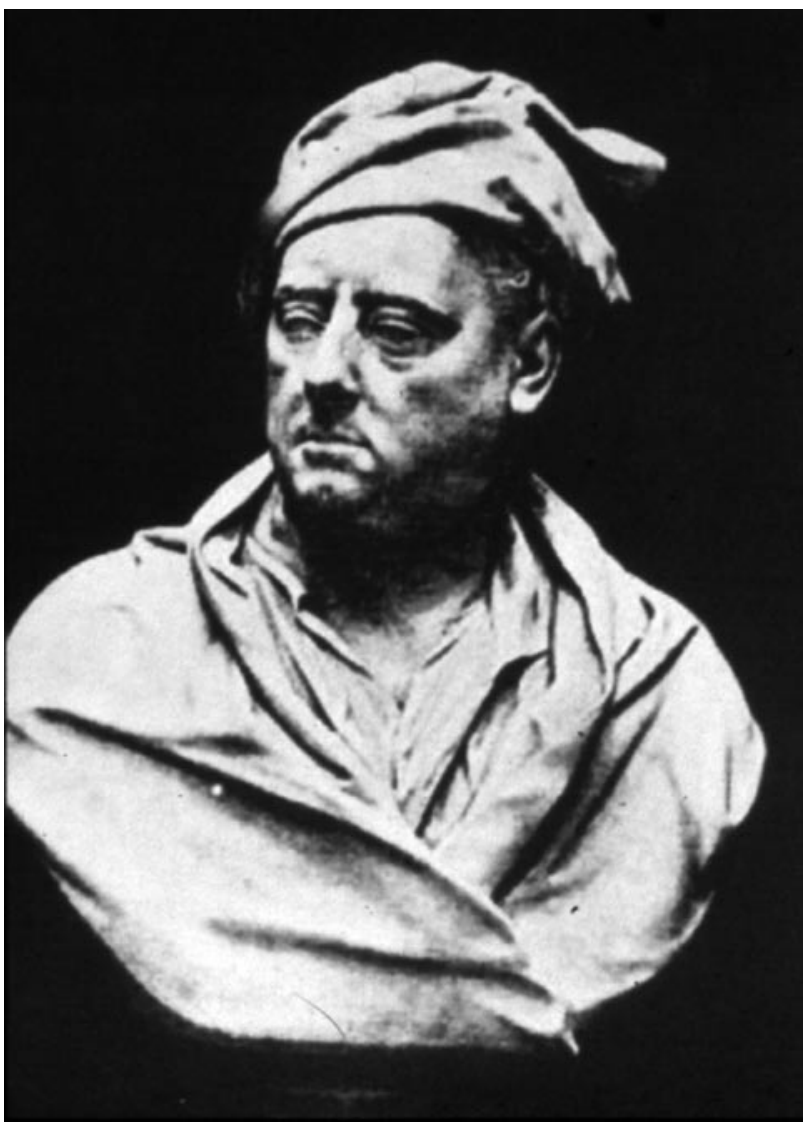

FIGURA 11. Busto de Cheselden por L.F. Roubillac. 
testículos y el desarrollo de la glándula prostática al observar que los animales castrados tenían una glándula de menor volumen. También describió el cuadro obstructivo que ocasiona el crecimiento prostático y su repercusión sobre el aparato urinario alto.

Falleció a la edad de 64 años y enterrado en los terrenos del Chelsea Hospital junto a su esposa Deborah y su hija Wilhelmina (Figura 10). Su memoria será recordada gracias al busto que Louis François Roubillac (también autor de los de Shakespeare, Newton, Hogarth y Handel y el mausoleo de lady Nigthingale) realizó y que se expone en el College of Phisicians de Londres (Figura 11).

\section{BIBLIOGRAFÍA}

1. URQUUHART-HAY, D.: "The Knife and the Stone". Aust. N. Z. Surg. (69), 267, 1999.

2. The Hektoen Inst. Of Medicine: Bulletin of the Society of Medical Story and Humanitis. Chicago, Spring Issue, 2006.

3. The Hektoen Inst. Of Medicine: Bulletin of the Society of Medical Story and Humanitis. Chicago, Summer Issue, 2006.

4. GIMÉNEZ, F.: "Hitos, mitos y ritos de la Urología". Europubli. S.L. Proyecto Omnicare.Yamanouchi Ed.

5. MARTÍ-IBÁÑEZ, F.: "The Epic of Medicine". M.D. Publications Inc. Bramhall House published. N.Y., USA, 1962. 